\title{
DEMOCRACIA E SOCIALISMO OPERÁRIO EM CASTORIADIS
}

\author{
DÉMOCRATIE ET SOCIALISME DE TRAVAIL EN CASTORIADIS
}

\begin{abstract}
RESUMO
A proposta de Cornelius Castoriadis é a da construção de uma sociedade autônoma. Para isso, faz-se necessário uma análise dos modos de sociedade heterônoma que se construíram até então, as quais são sociedades capitalistas, tanto de um capitalismo burocrático fragmentário (no bloco ocidental), quanto de um capitalismo burocrático total (no bloco soviético). Para haver a ruptura completa com estes tipos de capitalismos, é necessário um horizonte democrático através da gestão operária da produção, algo que romperá com a histórica divisão entre dirigentes e executantes e com a divisão de poder na sociedade. Sua crítica à burocracia, como elemento que impediu o alcance pleno do socialismo, e sua proposta de uma democracia operária são elementos fundamentais para o surgimento da autonomia do cidadão moderno, bem como de toda a sociedade moderna.
\end{abstract}

Palavras-chave: Democracia; Burocracia; Cidadão; Socialismo; Gestão.

\begin{abstract}
ABSTRAIT
La proposition de Cornelius Castoriadis est de construire une société autonome. Pour ce faire, il est nécessaire d'analyser les formes hétéronomes de la société qui ont été construites jusque-là, qui sont des sociétés capitalistes, à la fois d'un capitalisme bureaucratique fragmentaire (dans le bloc occidental) et d'un capitalisme bureaucratique total (dans le bloc soviétique). Afin d'avoir une rupture totale avec ces types de capitalismes, un horizon démocratique est nécessaire à travers la gestion de la production, quelque chose qui va rompre avec la division historique entre les dirigeants et les exécuteurs et avec la division du pouvoir dans la société. Sa critique de la bureaucratie, en tant qu'élément qui a empêché la pleine portée du socialisme, et sa proposition pour une démocratie ouvrière sont des éléments fondamentaux pour l'émergence de l'autonomie du citoyen moderne aussi bien que de toute la société moderne.
\end{abstract}

Mots-clés : Démocratie ; Bureaucratie ; Citoyen ; Socialisme ; Gestion.

\footnotetext{
${ }^{1}$ Mestrando em Filosofia pela Universidade de Brasília (UnB).

CV Lattes: http://lattes.cnpq.br/5411621520588310.
} 


\section{Introdução}

O presente artigo se ocupará por abordar o pensamento de maturidade de Cornelius Castoriadis no período anterior a toda sua reflexão acerca do imaginário radical presente em sua obra mais difundida, A instituição imaginária da sociedade. O texto se ocupará em grande parte por fazer uma exposição descritiva sobre o funcionamento da gestão operária, a qual se torna tema relevante no percurso intelectual do autor porque sua discussão ocorre após um longo período de críticas à burocracia soviética. Faz-se necessária uma exposição sobre o ponto central do pensamento de Castoriadis, que é justamente a crítica da burocracia em geral e da burocracia soviética em particular. Isto se deve porque ao analisar o que foi a burocracia soviética e como ela não representou para o autor um modelo de socialismo, pode-se pensar na construção de termos antinômicos à burocracia, justamente o socialismo e a democracia. Após a crítica sobre o que não é o socialismo e sobre o que ele deveria ser (em uma espécie de desvelamento), pode-se pensar no alcance da democracia como resultado do alcance do socialismo.

\section{A revolução que não levou à autonomia}

Ao contrário de Trotsky, cuja burocracia russa seria uma degenerescência da Revolução de Outubro, Castoriadis entende que a burocracia é mais do que apenas um elemento tido como passageiro. Ela é a essência da não realização por completo da Revolução, onde tornou por expandir-se para outros países levando seu modelo de governança e autoritarismo, levando sua base ideológica e sua divisão social. Ela saberia se adaptar ao meio sócio histórico e moldá-lo a si. Ela não é fruto apenas de uma "revolução incompleta" com uma perspectiva de vir a perecer naturalmente após os rumos da Revolução serem retomados. Ela é a própria causa da incompletude da Revolução, e é também a explicação do porque a Revolução Russa não propiciou um modelo de socialismo (sociedade autônoma), na qual, para o autor francês, ela representa mais um modelo de sociedade heterônoma. Castoriadis infere que, mesmo com esta experiência socialista, a humanidade ainda estaria buscando alcançar a autonomia.

Diz ele acerca do presente exposto: 
A burocracia não era, pois, excepcional nem uma formação transitória em qualquer sentido não sofisticado deste termo. Ela não era tão pouco uma simples camada parasitária, mas exatamente uma classe dominante que exerce um poder absoluto sobre o conjunto de toda a vida social e não somente estrita na esfera política. (CASTORIADIS, 1979, p. 14)

Ao chegar à França, Castoriadis, junto a Claude Lefort e outros companheiros, criou o grupo Socialisme ou Barbarie, com o objetivo de publicar artigos acerca da situação presente do proletariado, do nível de alcance da revolução socialista no mundo, dos aparelhos burocráticos soviéticos. $\mathrm{O}$ estudo da burocracia representa o tema central dos interesses deste “primeiro Castoriadis". Para ele, a URSS representava "o maior coveiro da revolução mundial” (CASTORIADIS, 1979, p. 81), pois ela impôs um modelo de organização social heterônomo e explorador ao invés de ser modelo de autogestão proletária e de emancipação, tanto social quanto da consciência aprisionada a uma hegemonia milenar de poder piramidal, onde a base da pirâmide continuou sendo representada pelos trabalhadores.

A burocracia, em sua forma moderna, está atrelada, intrinsecamente, ao modo de produção capitalista. Não desvencilhar a técnica da produção capitalista ao implantar o socialismo é um dos erros que permitem o crescimento da burocracia. A burocracia soviética representa uma nova classe social no lugar de uma burguesia. Ela se apropriou dos meios de produção e do Estado, de modo que, enquanto as burocracias capitalistas são fragmentárias, com uma separação aparente (formal) entre o Estado e o mercado, na burocracia soviética é o próprio Estado que age como controlador da produção econômica, alijando assim os trabalhadores do controle imediato dos meios de produção, objetivo este basilar na Revolução. Castoriadis acredita que a planificação e a estatização da economia não são os fatores elementares para o alcance do socialismo. Se ambos forem precedidos de um aparelho burocrático, serão convertidos em forma legal de exploração da uma classe (proletariado) por outra (burocracia).

O socialismo ou a sociedade autônoma tem como um de seus pilares o controle proletário da economia. Se não há este controle não pode haver socialismo. Essa burocracia surge como divisão entre dirigentes e executantes, ao passo que ela absorve a aristocracia operária (sindicalistas, engenheiros, técnicos) separando-a da massa para mantê-la em controle. Se no capitalismo tem-se uma forma de alienação do trabalhador visando o lucro, a burocracia soviética tem-se uma alienação ontológica visando alienar o proletariado da ideia de que ele é senhor do Estado e dos meios de produção, e que este mesmo Estado deve definhar 
completamente. $\mathrm{O}$ trabalhador deixa de ser para-si e torna-se em-si como peça ou autômato para produzir mais e de forma inconsciente.

A origem do capitalismo burocrático remonta ao fim do capitalismo concorrencial e sua consequente concentração de capital com um afunilamento natural em forma de concentração das forças produtivas. Com a expansão dos mercados no final do século XIX e com a super industrialização dos países imperialistas, o capitalismo tornou-se global, pois integrou o sistema mundial. Chegava-se ao capitalismo monopolista, o qual tendia a organizar a produção mundial de forma mais "racional", e, como fator mais importante, o desaparecimento do "patrãodiretor", intimamente ligado à empresa e mais próximo dos trabalhadores para dar lugar ao monopólio de grandes empresas e grandes capitais nas mãos de poucos. Isso gerou um distanciamento maior entre os operários e o capital, onde o capitalismo adquire uma forma mais burocrática.

Pode-se entender que a burocracia é vista falsamente como uma etapa posterior ao capitalismo, quando, na verdade, ela está imanente ao modo de produção capitalista, que foi levado e reproduzido na URSS no que tange ao trabalho na indústria. O Estado mantém uma relação de certa simbiose com o capitalismo, servindo-lhe como investidor e mantenedor da ordem social e lhe introjetando sua forma burocrática de agir.

\section{O socialismo operário segundo Castoriadis}

Castoriadis disserta sobre a necessidade de uma análise da experiência socialista desde 1917, a qual não proporcionou o alcance completo do socialismo e sim a substituição de uma sociedade de exploração por outra, esta burocrática e estatal. Sua análise tem como objeto a experiência real, de modo a propor outra teoria para a superação deste tipo de "socialismo" que se instaurou. O socialismo pressupõe o alcance da autonomia do proletariado. Esta é construída quando há democracia, por isto o seu conteúdo deve ser reordenado para que seja verdadeiramente criado.

As teses centrais sobre socialismo, segundo Castoriadis, são que: deve-se eliminar a contradição entre dirigentes e executantes; que deve surgir uma consciência socialista, o que implica em uma paralela eliminação da contradição anteriormente dita, o alcance da gestão operária e da democracia direta pelo proletariado. O socialismo não deve visar 
apenas à nacionalização, planificação ou a tomada de poder da burguesia e não deve limitar-se a uma análise supra-econômica da sociedade. Nas palavras do autor:

[...] o socialismo visa dar um sentido à vida e ao trabalho dos homens, permitir a sua liberdade, a sua criatividade $e$ a sua positividade se desenvolverem, criar laços orgânicos entre o indivíduo e seu grupo, entre o grupo e a sociedade, reconciliar o homem consigo mesmo e com natureza. (CASTORIADIS, 1983, p. 76)

Socialismo é democracia e autonomia. É auto-organização da sociedade por ela mesma, na qual seus interesses não se limitam apenas à destruição da classe dominante, ou ao controle operário do trabalho, e sim, diferentemente do que ela chama de capitalismo burocrático, tanto fragmentário quanto total que controle biopoliticamente a sociedade, o socialismo é o organismo social funcionando em comunhão e forjando as suas leis, suas riquezas e seu imaginário.

A base da exploração capitalista consiste na existência de uma classe dirigente, a qual é, em essência, heterônoma em relação à sociedade e que detém a posse ou o apoio do Estado. Ou seja, esta classe, além de controlar os meios de produção, rege os organismos de Estado e dita os rumos da vida das pessoas. Isso serve tanto para o capitalismo liberal (praticado no Ocidente) quanto para o burocrático (praticado no bloco soviético e na China). O capitalismo nega potencialidade dessa sociedade tal qual um parasita e somente pode existir na ausência de consciência social. Entretanto, ele gera um inconformismo nas pessoas, as quais podem destruílo. Faz-se necessário notar que alguns movimentos insurgentes que existiram na URSS, tais como a "Primavera de Praga", ou a "Revolução Húngara" eram movimentos populares contra a burocracia que se instalou, contra ao tipo de capitalismo burocrático total que se instalou e não contra o socialismo. Isso demonstra que o socialismo carece de democracia, gestão operária para existir tal como foi elencado anteriormente. (CASTORIADIS, 1983, p.79)

A crise constante no capitalismo consiste no seu desperdício das potencialidades da sociedade ao burocratizar o trabalho visando abortar qualquer resquício de autonomia operária, onde, para isso, escolhem-se dirigentes com a função de coagir o restante dos trabalhadores. Em suma, a hierarquia no trabalho tem mais função coercitiva do que laboral ou técnica. Os trabalhadores não são livres para pensar em reger seu trabalho, eles se tornam limitados por um sistema que quer mais controlá-los do que os dirigir. 
A sociedade autônoma ou socialismo depende do alcance da autonomia política e da autogestão do trabalho além do fim da sociedade de classes. Tal como diz Castoriadis:

O conteúdo da organização socialista da sociedade é primeiramente a gestão operária. Esta gestão a classe operária reivindicou e lutou para realizá-la nos momentos de sua ação histórica: na Rússia em 1917-18, na Espanha em 1936, na Hungria em 1956. (1983, p. 80)

A gestão operária inicia-se nas empresas (cf. CASTORIADIS 1979, p. 81). Os operários devem formar conselhos nas fábricas e delegar representantes para propor e debater suas questões. Estes conselhos podem ser dissolvidos a qualquer momento e são submissos à autoridade da massa operária. Eles são formados por operários que continuam mantendo suas atividades nas fábricas. Isto é a base de uma democracia direta, a qual seria superior à democracia grega, pois não teria o mesmo caráter excludente desta. Estes conselhos são o primeiro elemento para uma sociedade socialista e autogovernada, os outros são assembleia central e o governo dos conselhos.

Castoriadis propõe uma democracia diferente de um parlamento, na democracia liberal, ou do capitalismo burocrático total, pois estes se mostraram independentes e usurpadores do poder popular, na qual, no máximo, convocam o povo a participar da política apenas nas eleições. O socialismo, para se manter, deverá incluir as pessoas na atividade política, em sua forma mais burocrática e institucional. A forma como é feita a política inibe o povo de conhecer como as leis são criadas ou sobre o funcionamento burocrático do poder. As novas instituições socialistas devem fazer sentido para as pessoas e para isso é necessária uma limpeza da máquina estatal de forma a facilitar seu entendimento. O povo deve compreender sua importância na política, compreender sobre as instituições e o que será deliberado nas assembleias. Isso o aproximará de um pensamento cada vez mais autônomo e manterá o socialismo funcionando. Diz ele que haverá naturalmente uma redução de informação a ser analisada pelo povo (CASTORIADIS, 1983, p. 83), porque também haverá uma redução de questões que são oriundas da sociedade heterônoma anterior.

A democracia é fundamental para a construção do socialismo. Essa democracia impõe o conhecimento político-burocrático por parte dos trabalhadores, os quais são chamados constantemente a decidirem suas vidas e não apenas a votar em um representante alienando o seu poder de decisão sobre o nomos. Essa via democrática pode ser iniciada com o que o autor chama de "células de base" (CASTORIADIS, 1983, p. 85) tal como modelo grego da democracia. Estas células são constituídas por trabalhadores que 
representariam seus semelhantes em comunidade, partilhando suas questões e deliberando sobre suas ações.

A democracia direta resolverá o problema da centralização do poder e, consequentemente, da burocracia no período de transição entre a revolução e tomada do Estado, e a sociedade socialista. Ele pensa que a alienação política não surge simplesmente na centralização, a qual é entendida como algo necessário. Ela surge quando um grupo ou instituição se coloca além da sociedade, de modo a analisá-la e a ditar seu rumo. Isso impediria a criação de uma nova sociedade de classes e de uma classe dirigente de estado. (CASTORIADIS, 1983, p. 87)

Esta democracia respeitará o poder que vem da base ao governo de conselhos, na qual ocorrerá uma relação de informações constante entre o governo e a base. As decisões do governo terão de ser avaliadas pela base, como em um constante referendo.

\section{Sobre o trabalho em uma sociedade socialista}

O socialismo tem por base o alcance de uma autonomia social sobre o trabalho, um domínio total por parte dos trabalhadores nunca visto, pois em nenhum momento da história da humanidade o trabalho foi pensado e controlado pelos trabalhadores, os executantes, os quais deveriam pensar e organizar uma autogestão operária (CASTORIADIS, 1983, p. 88). Controlar o trabalho significa ter autonomia sobre a produção e sobre a economia. O povo, dominando a atividade laboral, pode pensar em melhorar sua vida, consciente de seus problemas, racionalizando, assim, a atividade social e a atividade laboral.

Autonomia tem início na gestão operária da produção e, em seguida, ela se expande à política. A consciência sobre o trabalho eleva a consciência política e a gestão operária elimina a burocracia que se impõe aos operários, os quais terão que ditar o ritmo de trabalho e o funcionamento das empresas através das assembleias. Segundo Castoriadis (1983, p. 90), "a gestão operária significa a reunificação das funções de direção e execução".

Um ponto fundamental a ser tratado em uma sociedade socialista é o domínio da tecnologia por parte dos trabalhadores e o seu uso consciente para melhorar sua atividade laboral, permitindo que os trabalhadores dominem o trabalho e não o contrário. $\mathrm{O}$ uso consciente da tecnologia pode inibir o desemprego estrutural e isto representa o que Castoriadis chama de "controle da atividade produtiva" (CASTORIADIS, 1983, 
p. 91 $)^{2}$. Segundo o autor, tal tecnologia desenvolve-se de modo a controlar o trabalhador para posteriormente alijá-lo de seu trabalho. Já a sociedade socialista escolheria pela tecnologia que for melhor para si em uma nova forma de racionalidade para além da racionalidade técnicoindustrial, pois caberá a ela analisar o impacto das novas tecnologias no trabalho e escolher entre aquelas que sejam eticamente benéficas a si. De nada adianta uma tecnologia que permite uma maior produção e que substitua grandes efetivos de trabalhadores. (CASTORIADIS, 1983, p. 91)

A gestão operária da empresa é algo que pode ser feito sem grandes dificuldades, pois os trabalhadores têm o conhecimento mais profundo sobre o funcionamento das empresas (CASTORIADIS, 1983, p. 98). Castoriadis (1983, p. 99) elenca quatro tipos de funções a serem realizadas em uma empresa socialista: a primeira refere-se às novas funções de coerção que serão autônomas, ou seja, não existirá o controle burocrático que existe nas empresas capitalistas e sim uma autodeterminação dos operários e uma autoridade construída por eles; a segunda é que os serviços que não são ligados à fabricação e, independente da empresa, farão parte dela e parte do sistema socialista como, por exemplo, serviço de contabilidade; a terceira, que as funções técnicas serão desmistificadas a todos os trabalhadores, isto romperá com a separação entre dirigentes técnicos e executantes, os técnicos podem surgir da massa operária, de modo que subordinada a ela não como o grupo dominante; a quarta, que as funções de direção, onde residem o núcleo da burocracia, serão diferentes das que existem no capitalismo, não haverá diretores separados dos operários e mais poderosos do que estes, e não haverá executivos que pensarão no mercado, pois a economia será planificada e controlada pelo povo. O que haverá será um conselho de delegados, como representantes operários, que tomarão decisões e se reunirão com frequência, ou, quando necessário, em uma assembleia geral operária que se reunirá uma ou duas vezes ao mês e deverá analisar as decisões dos conselhos.

O filósofo greco-francês faz uma descrição das tarefas de uma empresa socialista sobre uma gestão operária e cabe destacar que a ideia principal é que a gestão operária controle não somente toda a logística de uma empresa (CASTORIADIS, 1983, p. 104), desde a obtenção e chegada de matéria-prima, até a obtenção do produto final, passando pela determinação dos ritmos de produção, horas de trabalho, onde o próprio trabalho, incluindo os meios de produção, especialmente instrumentos de produção, será transformado pelos operários e será determinado

\footnotetext{
2“O capitalismo criou uma tecnologia capitalista". Ibidem, p, 92. Esta tecnologia desenvolve-se de modo a controlar o trabalhador, e, posteriormente, alijá-lo de seu trabalho, mesmo necessitando da criatividade deste. Na obra A instituição imaginária da sociedade e na obra supracitada, Castoriadis afirma que isto é a contradição do capitalismo.
} 
por estes, e não o contrário. O que gera uma autonomia no trabalho em oposição à alienação capitalista.

A gestão operária teria um contato maior com o consumidor produzindo aquilo que a população precisa e aquilo que ela deseja. A sociedade socialista não será determinada pelas fábricas e nem será alijada do processo produtivo.

É necessária uma simplificação da economia para que ela possa ser conhecida pelo povo e que este detenha o controle. Isso é fundamental para as atividades democráticas. O povo deve ter consciência para poder deliberar nas assembleias gerais.

\section{Igualdade salarial como pressuposto de uma sociedade socialista}

Um ponto bastante peculiar no pensamento de Castoriadis é sua defesa de um igualitarismo salarial para todas as funções, fato este comungado por Fidel Castro (cf. A grande tarefa da revolução é formar o homem novo, 2016). A igualdade absoluta dos salários é importante para dissuadir a presença de uma exploração na sociedade. Nem a especialização das profissões poderia ser uma justificativa para impedir essa desigualdade, visto que a sociedade é quem investiria na formação do trabalhador mais especializado, o qual dará um retorno social a ela. A igualdade dos salários é importante também para equipar o poder de consumo e criar uma consciência sobre o consumo justo e adequado.

A sociedade socialista é aquela que rompe com a economia historicamente existente na sociedade e alcança o estado tal de autonomia que possa decidir sobre o seu destino econômico. A sociedade socialista, sociedade autônoma, é livre ao determinar os seus objetivos e os seus limites, ao ser ela mesma a determinar a sua coerção. Ela não fica excluída das decisões que lhe importam e nem aliena seu poder democrático a um grupo especial ou grupo de especialistas. A própria racionalidade humana é o que ditaria os rumos da vida como bios e nomos, e avaliaria este nomos sempre que julgar necessário.

\section{Sobre a economia socialista}


A gestão da economia assim como a gestão operária da empresa é uma gestão democrática. Entretanto, a diferença que essa gestão é mais ampla do que a anterior porque ela refere-se à economia tanto micro quanto macroeconômica. $\mathrm{O}$ povo deverá ter conhecimento dos dados e informações referentes às empresas, à produção, à taxa de consumo e à matériaprima; e repensar a sua economia constantemente escolhendo assim, por exemplo, gastar melhor da melhor forma possível nas empresas.

O trabalho deixará de ser um fardo e se tornará edificante e a sociedade não viverá apenas para produzir bens de consumo, porém irá produzir sem a mentalidade capitalista anterior. O socialismo trará uma nova relação entre homem e o trabalho e as novas relações entre o campo e a cidade e entre trabalho intelectual e trabalho manual.

6. Sobre a gestão da sociedade socialista, a democracia por conselhos e o alcance da autonomia

A gestão da sociedade é o passo seguinte da construção de uma democracia direta no socialismo. Ela é concomitante à gestão operária, todavia, diferentemente dela, tem uma função de pensar o estado e a sociedade civil que se estabeleceu as assembleias e os conselhos representam todo poder instituído em forma de uma comunidade em oposição ao estado tal qual ela apresenta para diferenciar a democracia antiga da moderna. O povo põe seu nomos e repensa constantemente sua sociedade e as novas instituições que se criaram, incluindo a gestão operária da economia. Essa gestão da sociedade não é mera administração executiva da população a qual é feita de forma heterônoma nos Estados modernos. Essa gestão é gérmen, o organismo vivo socialista interdependente e reflexivo. Nesta forma de democracia, na democracia direta não há um norte fixo, uma lei transcendente ou valores imutáveis a dominar a bios e impedir a vontade popular de se concretizar.

Os conselhos operários terão sua autonomia de forma entrelaçada com os interesses de toda sociedade. Isso significa que os trabalhadores dos diferentes setores, inclusive os do campo, que formam suas comunas rurais, deliberarão com a nova comunidade sobre seus lucros, investimentos, condições de trabalho, etc. Em suma, discutirão sobre como gerir seus recursos e como repartir seus ganhos. A isso também cabem aos conselhos a tarefa de gerir as instituições sociais desta sociedade autônoma. (CASTORIADIS, 1983, p. 131-132) 
Estes conselhos representarão não apenas a forma de gestão das empresas, mas a primeira parte do processo de democracia de base na sociedade autônoma. (CASTORIADIS, 1983, p. 134) Como se mostrarão uma parte fundamental da vida em sociedade, os conselhos representarão algo além de um agrupamento político na empresa e sim fará parte da vida pública da sociedade. Isso se deve pela sua tomada democrática das funções do Estado capitalista anterior, eliminando assim a relação de outrora entre a classe dominante e a burocracia, ou eliminando a própria burocracia como classe social, pois, caberão aos conselhos a direção dos bens e das empresas públicas, bem como da polícia, da Justiça e da educação em fases iniciais. (CASTORIADIS, 1983, p. 135)

Os representantes dos conselhos das assembleias dos conselhos e de seu respectivo "governo" podem ser destituídos a qualquer momento. Isso já faz romper com o surgimento de uma nova burocracia que se arrogue o direito de estar no poder por ser considerar a mais apta a governar. Cabe aos trabalhadores a aptidão ou simplesmente a doxa para a tomada das decisões políticas e não um grupo de representantes imutáveis e "seletos". A destituição dos representantes a qualquer momento é fundamental para a manutenção de uma democracia direta, bem como é fundamental o direito a revogação popular das decisões das assembleias centrais e das assembleias gerais dos conselhos que lhes achar necessário. Um órgão democrático não pode impor as suas decisões sobre a vontade popular, por isto, cada decisão sua é referenciada pelo povo e à sua decisão estes órgãos devem obediência. Se isto não for feito há um retorno à democracia liberal, onde o Parlamento pouco se importa com a vontade popular e as pessoas convivem em uma ditadura jurídico-burocrática travestida de democracia.

A democracia operária, democracia direta ou democracia de base, terá início nos conselhos de fábrica e na assembleia geral dos mesmos como microcosmo da democracia das instancias "superiores". Em seguida, haverá uma assembleia geral destes conselhos, a qual deliberará questões mais complexas, mais abrangentes que abordem as questões de todos os conselhos. (CASTORIADIS, 1983, p. 140) Ela será formada por delegados eleitos nas assembleias gerais, as quais poderão formar uma espécie de governo designado a compor uma espécie de poder executivo dentro destas assembleias. Estes serão mudados frequentemente e prestarão contas de suas decisões a toda assembleia, podendo ter suas decisões revogadas ou acatadas, assim como os seus mandatos a qualquer momento revogáveis. (CASTORIADIS, 1983, p. 141) Para isto ocorrer, faz-se necessário um desenvolvimento da consciência democrática, de modo que o povo eleve o seu nível de informação sobre os temas pela já supracitada simplificação das informações, quanto pelo desenvolvimento de uma técnica que permita o maior alcance possível das decisões das assembleias para 
o entendimento geral e o maior alcance da expressão da vontade popular. A isto Castoriadis cita a necessidade da busca por uma técnica socialista, que nunca foi buscada pela técnica capitalista (pois ele crê que a técnica em geral não é neutra) para o desenvolvimento de uma inclusão do povo nas questões políticas e para o alcance de uma democracia direta em um Estado muito maior e mais populoso que as poleis gregas. (1983, p. 144)

\section{Conclusão}

Castoriadis faz uma análise da burocracia como elemento de suma importância para o desenvolvimento do capitalismo contemporâneo e do não alcance do socialismo pelos Estados pretensamente socialistas. Seu intuito é demonstrar como o socialismo é dependente de uma atividade democrática constante, onde o poder popular relaciona-se dialeticamente com o trabalho e com a atividade política.

Para este socialismo existir é necessário que a estrutura de classe no Estado deixe de existir. Esta estrutura milenar e hierarquizada está para além de ser apenas uma classe parasitária, como diria Marx em Crítica da Filosofia do Direito de Hegel, ela está no cerne do poder relacionando-se mutuamente com a classe economicamente dominante, tendo, por fim, fundindo-se com esta, formando o capitalismo burocrático.

Logo após a destruição da burocracia, precedida pela tomada dos meios de produção, o socialismo tentará alcançar uma democracia direta em forma de democracia operária, democracia de base ou democracia de conselhos. Isto fará com que seja propício o surgimento do que o autor entende ser a sociedade autônoma, o verdadeiro socialismo. Esta sociedade rompe com a heteronomia milenar das classes dominantes da economia e do Estado acerca das instituições sociais, de modo que seja ela mesma a construir seu ethos, buscando a igualdade e a democracia. Igualdade é igualdade de poder, sem igualdade não há liberdade para todos e sem esta não há autonomia

O socialismo operário é construído por Castoriadis como um modelo que deve ser regulado pelo povo, e não como uma cartilha ou manual. Seu entendimento é que a ruptura da divisão de poder entre as classes dirigentes (burocracia, altos funcionários das empresas, técnicos, engenheiros e gerentes das mesmas), e as classes dirigidas é fundamental para a horizontalidade necessária a uma empresa socialista. Este socialismo começa na gestão das empresas e deve se expandir ao controle político da sociedade. 
Portanto, buscar o socialismo é buscar, antes de tudo, a ruptura do sistema que controla o Estado e os meios de produção, implantando uma democracia a mais inclusiva possível, totalmente sujeita à vontade popular e alcançando a igualdade de poder dentro dos ambientes de trabalho. A sociedade autônoma é aquela que se constrói com a destruição das estruturas ideológicas dominantes e cerceadoras da consciência social, alcançando, assim, um estágio de democracia que permita a todos a autonomia individual e a defesa da verdadeira justiça no trabalho feito por esta sociedade. 
Referências

CASTORIADIS, Cornelius. A criação histórica. O Projeto da Autonomia. Porto Alegre: Prefeitura Municipal, 1992.

. A instituição imaginária da sociedade. Rio de Janeiro: Paz e Terra, 2007.

. A sociedade burocrática 1: as relações de produção na Rússia. Porto,

Afrontamento, 1979.

. Socialismo ou Barbárie: o conteúdo do socialismo. São Paulo,

Brasiliense, 1983.

CASTRO, Fidel. A grande tarefa da revolução é formar o homem novo. São Paulo, Expressão Popular, 2016.

MARX, Karl. Crítica da filosofia do direito de Hegel. São Paulo: Boitempo, 2010. 